\title{
Antimicrobial Activity Of Soft Liner Incorporated With Ocimum Sanctum Extract
}

Research Article

Gowtham Neppala ${ }^{1}$, Subhabrata Maiti ${ }^{*}$, S Rajeshkumar ${ }^{3}$, Dhanraj Ganapathy ${ }^{4}$

${ }^{1}$ Saveetha Dental College and Hospitals, Saveetha Institute of Medical and Technical Sciences Saveetha University, Chennai-600077, Tamilnadu, India.

${ }^{2}$ Assistant Professor, Department of Prosthodontics And Implantology, Saveetha Dental College And Hospitals, Saveetha Institute Of Medical And Technical Sciences, Saveetha University, Chennai-600077, Tamilnadu, India.

${ }^{3}$ Associate Professor, Department of Pharmacology, Saveetha Dental College and Hospitals, Saveetha Institute of Medical and Technical Sciences Saveetha University, Chennai-600077, Tamilnadu, India.

${ }^{4}$ Professor and Head, Department of Prosthodontics And Implantology, Saveetha Dental College And Hospitals, Saveetha Institute Of Medical And Technical Sciences, Saveetha University, Chennai-600077, Tamilnadu, India.

\section{Abstract}

Background: Tissue conditioners are soft denture liners which are commonly applied to the fitting surface of a denture. Ocimum sanctum (Tulsi) is a legendary herb which has been used for ages also helps in treating oral diseases because of its antibacterial, anti inflammatory, ulcer healing, antioxidant, immunomodulatory properties.

Aim: The aim of present study is assessing the antimicrobial effect of addition of Ocimum sanctum extract into denture soft liner Materials and Methods: The study employed is an in vitro experimental design. Ocimum sanctum extract is incorporated into Temporary denture soft liner (GC soft liner,GC Corporation, Tokyo, Japan) and these specimen are kept in the Blood Agar media for 3 microorganisms namely Candida albicans, Streptococcus mutans, Lactobacillus and all the culture plates are incubated for 24 hours under room Temperature and Zone of Inhibition is calculated in the Agar media using measuring tape.

Results: by The zone of inhibition in Streptococcus was maximum for Dipped with Tulsi $(24.33 \pm 1.155)$ and minimum Without Tulsi $(10.33 \pm 0.557)$, the mean difference among groups was statistically significant $(p<0.05)$ and in candida the zone of inhibition was maximum for Dipped with Tulsi $(22.00 \pm 1)$ and minimum in Without Tulsi $(10.67 \pm 0.577)$, the mean difference among groups was statistically significant $(\mathrm{p}<0.05)$.

Conclusion: Addition of Ocimum sanctum extract in denture soft liner showed considerable antimicrobial activity in Streptococcus mutans and Candida and minimum efficacy in lactobacillus.

Keywords: Denture Liners; Tulsi; Ocimum Sanctum; Denture Stomatitis; Candida.

\section{Introduction}

The scientific name of tulsi is 'Ocimum sanctum Linn'.Ocimum sanctum has been used for thousands of years for its healing properties and is regarded in Ayurveda as the "elixir of life" that promotes longevity [1]. As Ocimum sanctum is effective in treatment of various medical disorders, It is also a very promising herb in management of oral diseases and dentistry. Ocimum sanctum leaves are quite effective in treating common oral infections. The Ocimum sanctum leaves contain strong antibacterials like carvacrol and terpene \& sesquiterpene b caryophyllene. Chewing of tulsi leaves help in maintenance of oral hygiene. The antibacterials present in Ocimum sanctum leaves are approved by FDA as food additive [2]. In a study conducted by Khan A et al., [3] it was concluded that linalool and eugenol which are present in essential oil extracted from Ocimum sanctum are effective against two strains of candida ( $C$. albicans and Candida tropicalis) Denture relining materials are used in sensitive patients and help in conditioning tissue and limit the traumatic effect of denture causing cushioning effect [4]. Denture relining material distribute the loads transferred to soft tissues during motion in Immediate denture. Soft lining materials are contaminated in the oral environment and are not

\author{
*Corresponding Author: \\ Subhabrata Maiti, \\ Assistant Professor, Department of Prosthodontics And Implantology, Saveetha Dental College And Hospitals, Saveetha Institute Of Medical And Technical Sciences, Saveetha \\ University, Chennai-600077, Tamilnadu, India. \\ Tel: 9007862704 \\ E-mail: drsubhoprostho@gmail.com \\ Received: November 12, 2020 \\ Accepted: November 27, 2020 \\ Published: December 03, 2020 \\ Citation: Gowtham Neppala, Subhabrata Maiti, S Rajeshkumar, Dhanraj Ganapathy. Antimicrobial Activity Of Soft Liner Incorporated With Ocimum Sanctum Extract. Int J
} Dentistry Oral Sci. 2020;S5:02:004:15-20. doi: http://dx.doi.org/10.19070/2377-8075-SI02-05004

Copyright: Subhabrata Maiti 2020 . This is an open-access article distributed under the terms of the Creative Commons Attribution License, which permits unrestricted use, distribution and reproduction in any medium, provided the original author and source are credited. 
possible to clean (or) brush effectively [5].

Denture-induced stomatitis are treated with antifungal drugs such as nystatin and fluconazole [6-8]. Although systemic dosage of antifungals may be effective against mucosal lesions, they are not effective for Candida infested denture fitting surface [6, 7]. Furthermore, these drugs are found to have toxic effect on human beings if it is overused. Hence, alternative antifungal agents extracted from the plants are being researched for the use of treating oral candidiasis. The most important advantage claimed for therapeutic use of medicinal plants in various elements is their safety besides economical, effective and easy availability.Denture disinfectant agents are Chlorhexidine gluconate, Sodium hypochlorite, Hydrogen peroxide might cause unfavourable changes in the physical and chemical properties of the softliner [9].

Micro porosities and roughness in the denture surface will lead to adherence of Candida albicans and formation of the colonies on the fitting surface of the denture. These microorganisms have to be removed by mechanical or chemical cleansing; however in some situations, there cannot be completely removed from the denture surfaces Polymethylmethacrylate (PMMA) is the most common material used in the fabrication of removable complete or Partial denture prosthesis [10]. The aim of the study was to evaluate the antimicrobial effect of Ocimum sanctum extract added to the soft liner on growth inhibition of C.albicans, lactobacillus, and S.mutans.

\section{Materials and Methods}

The study done was an in vitro experimental design.

\section{Preparation of Ocimum sanctum extract}

A Total of 250 grams of finely powdered and macerated Ocimum sanctum powder is taken and mix it in $100 \mathrm{ml}$ of distilled water in a beaker. The solution is Heated for $2-3$ hours at $60^{\circ} \mathrm{C}$ and allowed to stand over for 4-5 hours. The prepared decoction was subjected to filtration with Whatman 11 filter paper to obtain a clear filtrate. The filtrate thus obtained was a solid residue of Tulsi extract approx $18 \mathrm{~g}$ of Thick residue is obtained.

\section{Specimen Preparation}

Preparation of Temporary soft liner: For $2.2 \mathrm{~g}$ of powder $1.8 \mathrm{~g}$ liquid (GC soft liner,GC Corporation, Tokyo, Japan) is mixed according to manufacturer's instructions and cut into $1 \mathrm{~cm}$ diameter and $1 \mathrm{~mm}$ thickness circle is prepared and separated in the petri dish and 6 discs are prepared using a special mould and cutting device.

Adding of Ocimum sanctum extract: For $2.2 \mathrm{~g} / 1.8 \mathrm{~g}$ liquid of soft liner $10 \mathrm{ml}$ of Ocimum sanctum extract is added and mixed and cut into $1 \mathrm{~cm}$ radius and $1 \mathrm{~mm}$ thickness circle is prepared and separated in petri dish some of the prepared specimen is just impregnated on the top using filler and separated in Petri dish.

Sterilization of Specimen: The specimens were handled carefully which includes the utilization of latex gloves for all phases and also while retrieving the specimens. All the specimens are kept in Laminar Airflow chamber for 2 hours.

Preparation of Agar Medium: Blood Agar medium is prepared and transferred to petri dish under aseptic conditions. Blood Agar preparation is done for 3 microorganisms namely Candida albicans, Streptococcus mutans, Lactobacillus and kept in Laminar air flow chamber for sterilization and grouped.

\section{Microbial Test}

The prepared Ocimum sanctum extract is inoculated into soft liner and are inoculated into Agar plates under aseptic condi-

Figure 1. Ocimum sanctum extract prepared.



Figure 2. Adding of Ocimum sanctum extract in to Softliner.

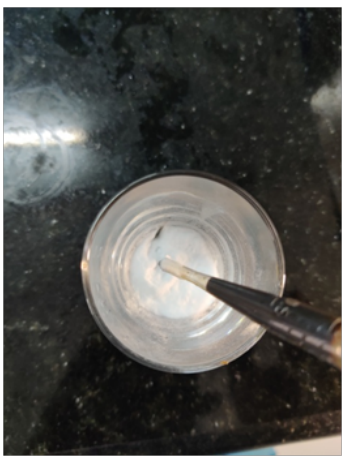


tions and grouped into 9 samples and 3 samples in each group Each group consists of microbes Lactobacillus, Streptococcus mutans, and Candida albicans which are divided into Control as group A, Softliner with Ocimum sanctum extract as group B and soft liner which is Dipped with Ocimum sanctum extract group $C$ same test was performed 3 times to eliminate bias.All culture plates are incubated for 24 hours under Room Temperature and Zone of Inhibition is calculated using measuring tape.

\section{Statistical Analysis}

Descriptive statistics was used to evaluate zone of inhibition of different microbes in the culture media. One Way Anova and Tukey HSD Post hoc test was performed and the $\mathrm{p}$ value was determined to evaluate the significance of the variables. The activity between different groups by zone of inhibition was evaluated and statistics were carried using SPSS Software version 23.0 by IBM India. The results were obtained in the form of tables and graphs.

\section{Results}

This study shows that adding Ocimum extract to soft liner shows anti microbial action in different culture media of which the zone of inhibition in lactobacillus group was maximum for Dipped with Tulsi $(17.67 \pm 1.528)$ and minimum in With out Tulsi $(10.33 \pm 0.557)$, the mean difference among groups was statisti- cally significant $(\mathrm{p}<0.05)$ followed by The zone of inhibition in Streptococcus was maximum for Dipped with Tulsi (24.33 1 1.155) and minimum Without Tulsi $(10.33 \pm 0.557)$, the mean difference among groups was statistically significant $(p<0.05)$ and in candida the zone of inhibition was maximum for Dipped with

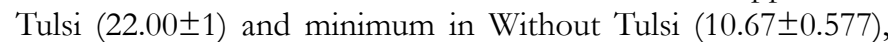
the mean difference among groups was statistically significant $(p<0.05)$ (Table 1). For pairwise Comparisons the mean difference between all the groups are statistically significant $(p<0.05)$, except between Impregnated vs Dipped in Lactobacillus and Without tulsi vs Impregnated in Streptococcus as $(\mathrm{p}>0.05)$ which is statistically insignificant (Table 2).

\section{Discussion}

Several plant products such as Ocimum sanctum, Neem, Lemon and others have been tested for their Antimicrobial properties in the past with considerable success. Resistance to currently used chemotherapeutics is the major factor that necessitates the search for alternative safe, efficacious and cost effective treatment options, particularly in developing countries.In this study, we attempted to obtain information on the Antimicrobial efficacy of Ocimum sanctum, particularly against Candida albicans, Lactobacillus and Streptococcus mutans as these microbes are more commonly associated with in the oral cavity. Results in this in vitro experiment showed that Ocimum sanctum has some antimicrobial features.

Table 1. Comparison of Zone of inhibition against 3 groups namely without Ocimum sanctum, Impregnated, Dipped.

\begin{tabular}{|c|c|c|c|c|c|}
\hline Microbes & Groups & Mean \pm SD & df & F & p-value \\
\hline Lactobacillus & Without Ocimum sanctum & $10.33 \pm 0.557$ & 2 & 33.881 & $0.001^{*}$ \\
& Impregnated & $15.00 \pm 1.00$ & & & \\
& Dipped & $17.67 \pm 1.528$ & & & \\
\hline Streptococcus mutans & Without Ocimum sanctum & $10.33 \pm 0.557$ & 2 & 168.778 & $0.001^{*}$ \\
& Impregnated & $12.67 \pm 1.155$ & & & \\
& Dipped & $24.33 \pm 1.155$ & & & \\
\hline Candida albicans & Without Ocimum sanctum & $10.67 \pm 0.577$ & 2 & 176.6 & $0.001^{*}$ \\
& Impregnated & $17.67 \pm 0.577$ & & & \\
& Dipped & $22.00 \pm 1.00$ & & & \\
\hline
\end{tabular}

*Statistically significant $\mathrm{p}<0.05 \mathrm{p}$-value was derived from one way ANOVA

Table 2. Pair wise comparison of three groups namely without Ocimum sanctum, Impregnated, Dipped on different microbes Lactobacillus,Streptococcus and Candida based on Zone of Inhibition.

\begin{tabular}{|c|c|c|c|c|}
\hline Microbes & Group & MD & SE & p-value \\
\hline Lactobacillus & Without Ocimum sanctum vs Impregnated & 4.66 & 0.903 & $0.005^{*}$ \\
\hline & Without Ocimum sanctum vs Dipped & 7.33 & 0.903 & $0.001 *$ \\
\hline & Impregnated vs Dipped & 2.66 & 0.903 & 0.058 \\
\hline Streptococcus & Without Ocimum sanctum vs Impregnated & 2.33 & 0.816 & 0.65 \\
\hline & Without Ocimum sanctum vs Dipped & 14 & 0.816 & $0.001 *$ \\
\hline & Impregnated vs Dipped & 11.66 & 0.816 & $0.001 *$ \\
\hline Candida & Without Ocimum sanctum vs Impregnated & 7 & 0.609 & $0.001 *$ \\
\hline & Without Ocimum sanctum vs Dipped & 11.33 & 0.609 & $0.001 *$ \\
\hline & Impregnated vs Dipped & 4.33 & 0.609 & $0.001 *$ \\
\hline
\end{tabular}

*The mean difference is significant at the 0.05 level and statistically significant $\mathrm{p}<0.05 \mathrm{p}$-value was derived from Tukey HSD Post hoc test. 
Figure 3. Petri dishes showing soft liner which is impregnated and dipped in Ocimum sanctum.
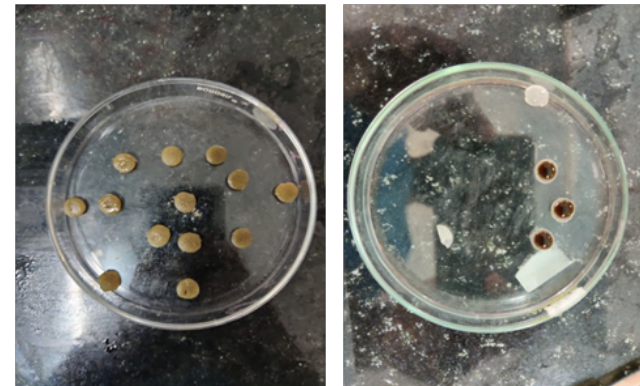

Figure 4. Mean plot showing the mean zone of inhibition in $(\mathrm{mm})$ for different groups in Lactobacillus.

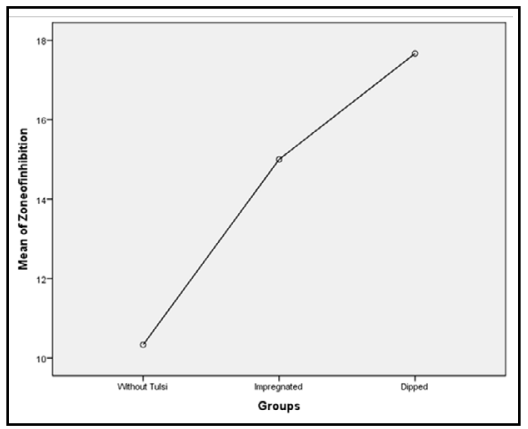

Figure 5. Mean plot showing the mean zone of inhibition in $(\mathrm{mm})$ for different groups in Streptococcus.

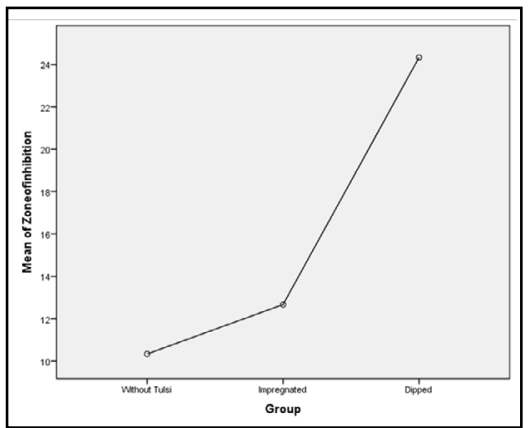

Figure 6. Mean plot showing the mean zone of inhibition in $(\mathrm{mm})$ for different groups in Candida.

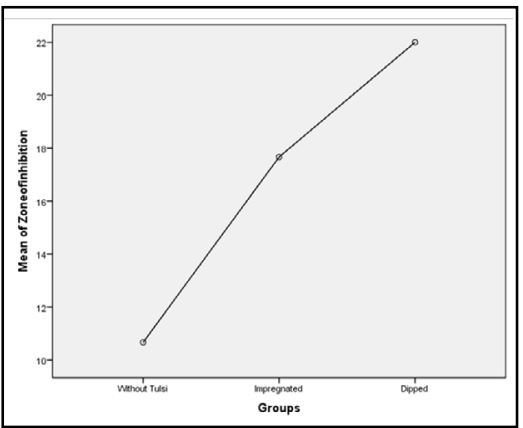

Figure 7. Zone of inhibition seen in different groups namely Candida,Lactobacillus and Streptococcus mutans.
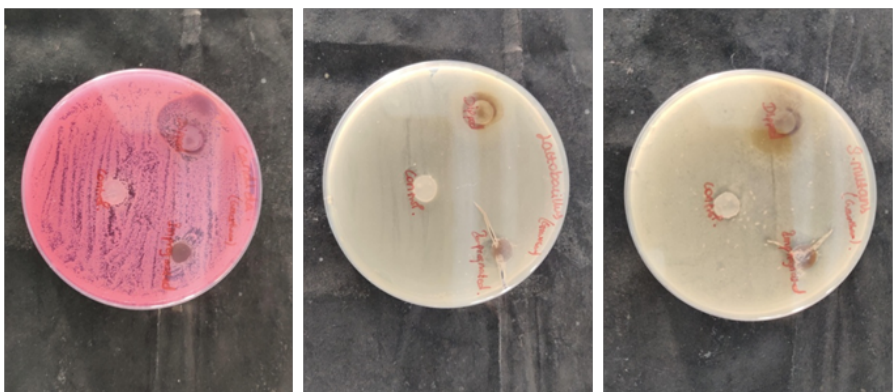
Different mechanisms of action of Ocimum sanctum have been proposed by many authors earlier. The leaves contain ascorbic acid and carotene as well as [11] Eugenol (1-hydroxy-2 methoxy4-allylbenzene) majority of active constituents present in O. sanctum have been found to be largely responsible for the therapeutic potentials. The other important constituents are carvacrol, methyl eugenol, Urosolic acid and caryophyllene [12]. A study shows the ethanolic extract of Ocimum sanctum L. showed antimicrobial activity against Streptococcus mutans and Lactobacillus acidophilus [13]. In a study by Vishwabhan et al., [14] proposed that antimicrobial activity of Ocimum sanctum by virtue of its essential oil content. Various other studies also project the idea that Ocimum sanctum yields various essential oils which are responsible for the medicinal purposes including antimicrobial, antioxidant, antifungal, anti inflammatory activities that can probably explain its activity against the microbes. A study by Lolayekar NV shows ithas the potential to be developed into an antimicrobial agent against cariogenic bacteria by chewing Ocimum sanctum leaves in children [15]. Ramesh et al, 2014 [16] stated that $>99 \%$ of germs and bacteria in the mouth that cause dental cavities, plaque formation, halitosis, etc., are destroyed by Ocimum sanctum, thus making it an excellent mouth freshener and an oral disinfectant. A study shows that Ocimum sanctum plant extracts have exhibited a strong inhibition of the growth, acid production, sucrose-induced adherence, and glucan-induced aggregation of s.mutants [17]. It has also been postulated that Ocimum sanctum has an immunomodulatory effect and acts by increasing the levels of interferon, IL-4 and T-Helper cells that can strengthen host response to infections. Ocimum sanctum enhances immunity and improves metabolic functions their extract has been found to reduce inflammation by inhibiting enzymes [18-20] it also lowers the stress and has antioxidant properties [12, 21, 22]. A study by Simonetti et al. verified that Grape Seed Extract in denture soft liner exhibited high antifungal activity against various strains of Candida both in vivo and in vitro [23]. A study by Neven $\mathrm{S}$ Aref et al concluded that $10 \% \mathrm{w} / \mathrm{w}$ Grape Seed Extract modified soft liner may be a promising formulation with antifungal activity might be used to generate clinically effective dental formulations to maintain oral health particularly for patients with removable prosthodontics [24]. A study on Chlorhexidine shows that PMMA (polymethyl methacrylate) and PEMA (polyethyl methacrylate) softliners with Chlorhexidine Diacetate incorporation had an inhibitory effect on C. albicans, once it was able to be released to a storage solution, and it also not clinically affected its hardness [25]. A study shows Soft lining denture materials combined with carvacrol has shown great in vitro antimicrobial activity against microorganism including oral pathogens [26] these are all chemical modification,hence present study can be much helpful as it is natural green mediated modifications without side effects a study showed the helpful effect of Ocimum sanctum and coined it as Queen of Herbs as it helps in improving the general health also $[27,28]$. The present study is one of the way to assess the Antimicrobial efficacy of Ocimum sanctum leaves extract in Denture soft liner for its Antimicrobial activity against Candida albicans, S.mutans, lactobacillus.

Ocimum sanctum is a legendary herb which has been used for ages due to its religious and medicinal values, several pharmacological studies have established a scientific basis for therapeutic uses of this plant. It can prove beneficial in treating oral diseases also because of its antibacterial, anti inflammatory, ulcer healing, antioxidant, immunomodulatory properties, with the basic limitations of the study design, generalizability is a possibility with fur- ther accumulation of evidence in this regard. However, within the limitations of the present study it could be concluded that Ocimum sanctum, as an adjunct, "if" found effective and safe on further research would be considered as a potential "adjunct" along with the standard care to overcome the side effects of synthetic drugs, especially in this era of ever advancing clinical dentistry.

\section{Limitations and Future Scope}

This particular study has lacks oral environment furthermore changes in hardness of denture base after incorporation of Ocimum sanctum extract. Further more confirmation with experiments conducted under in vivo conditions. Future scope of this study is adding Ocimum sanctum to soft liner or in combination with soft liner shows Anti-Inflammatory action as it is a medicinal herb which is readily available in our surrounding habitat and it also shows slow and steady release of anti-inflammatory substitutes and it does not shows any side effects. So it is used in any material and see changes and mechanical properties of the material after adding Ocimum sanctum extract and it has various clinical significances in implant dentistry, Immediate denture and Maxillofacial prosthesis.

\section{Conclusion}

Within the limits of this study it is presumed that Ocimum sanctum extract in denture soft liner showed considerable antimicrobial efficacy in groups in Streptococcus mutans, Candida and minimum efficacy in lactobacillus. Ocimum extract would be considered as a potential adjunct along with the standard care in the management of denture stomatitis and also to overcome side effects of synthetic drugs.

\section{References}

[1]. Prakash J, Gupta SK. Chemopreventive activity of Ocimum sanctum seed oil. J Ethnopharmacol. 2000 Sep;72(1-2):29-34.Pubmed PMID: 10967450.

[2]. Agarwal P, Nagesh L; Murlikrishnan. Evaluation of the antimicrobial activity of various concentrations of Tulsi (Ocimum sanctum) extract against Streptococcus mutans: an in vitro study. Indian J Dent Res. 2010 JulSep;21(3):357-9.Pubmed PMID: 20930344.

[3]. Khan A, Ahmad A, Manzoor N, Khan LA. Antifungal activities of Ocimum sanctum essential oil and its lead molecules. Nat Prod Commun. 2010 Feb;5(2):345-9.Pubmed PMID: 20334156.

[4]. Saravanan M, Kumar A, Padmanabhan TV, Banu F. Viscoelastic properties and antimicrobial effects of soft liners with silver zeolite in complete dental prosthesis wearers: an in vivo study. Int J Prosthodont. 2016 MayJun;28(3):265-9.Pubmed PMID: 25965641.

[5]. Dimiou AM, Michalakis K, Pissiotis A. Influence of thickness increase of intraoral autopolymerizing hard denture base liners on the temperature rise during the polymerization process. J Prosthet Dent. 2014 Jun;111(6):51220.Pubmed PMID: 24360010.

[6]. Kumar SM, Kumar VA, Natarajan P, Sreenivasan G. Antifungal Efficacy and the Mechanical Properties of Soft Liners against Candida albicans after the Incorporation of Garlic and Neem: An In vitro Study. J Int Soc Prev Community Dent. 2018 May-Jun;8(3):212-217.Pubmed PMID: 29911057.

[7]. Budtz-Jörgensen E, Stenderup A, Grabowski M. An epidemiologic study of yeasts in elderly denture wearers. Community Dent Oral Epidemiol. 1975 May;3(3):115-9.Pubmed PMID: 1056815.

[8]. Sholapurkar AA, Pai KM, Rao S. Comparison of efficacy of fluconazole mouthrinse and clotrimazole mouthpaint in the treatment of oral candidiasis. Aust Dent J. 2009 Dec;54(4):341-6.Pubmed PMID: 20415933.

[9]. Kasuga Y, Takahashi H, Akiba N, Minakuchi S, Matsushita N, Hishimoto M. Basic evaluation on physical properties of experimental fluorinated soft lining materials. Dent Mater J. 2011;30(1):45-51.Pubmed PMID: 21282889.

[10]. Przybyłowska D, Mierzwińska-Nastalska E, Swoboda-Kopeć E, Rubinsztajn 
R, Chazan R. Potential respiratory pathogens colonisation of the denture plaque of patients with chronic obstructive pulmonary disease. Gerodontology. 2016 Sep;33(3):322-7.Pubmed PMID: 25393518.

[11]. Medical and arometic plants Abstracts publication and information Directorate, CSIR, Hillside Road, New Delhi 110012 India [Internet]. Vol. 32, Biologia Plantarum. 1990. p. 112-112. Available from: http://dx.doi. org/10.1007/bf02897550

[12]. Kousik DM, Kumar B. A REVIEW ON THERAPEUTIC USES OF OCIMUM SANCTUM LINN (TULSI) WITH ITS PHARMACOLOGICAL ACTIONS. Int J Res Ayurveda Pharm. 2012 Sep 1;3(5):645-7.

[13]. Gadiyar A, Ankola AV, Rajpurohit L. Evaluation of the Antimicrobial Activity of Ocimum Sanctum L.(Tulsi) Extract against Streptococcus Mutans and Lactobacillus Acidophilus-An in-Vitro Study. Int J Health Res. 2017;7:2248.

[14]. Vishwabhan S, Birendra VK, Vishal S. A review on ethnomedical uses of Ocimum sanctum (Tulsi). Int Res J Pharm. 2011;2:1-3.

[15]. Lolayekar NV, Kadkhodayan SS. Estimation of salivary pH and viability of Streptococcus mutans on chewing of Tulsi leaves in children. J Indian Soc Pedod Prev Dent. 2019 Jan-Mar;37(1):87-91.Pubmed PMID: 30804313.

[16]. Ramesh G, Nagarajappa R, Madhusudan AS, Sandesh N, Batra M, Sharma $\mathrm{A}$, et al. Estimation of salivary and tongue coating $\mathrm{pH}$ on chewing household herbal leaves: A randomized controlled trial. Anc Sci Life. 2012 Oct;32(2):69-75.Pubmed PMID: 24167330.

[17]. Haque E, Australian Institute for Innovative Materials, University of Wollongong, NSW, Australia, School of Chemical and Biomolecular Engineering, et al. A Systematic Review for Anterior Cruciate Ligament Reconstruction [Internet]. Vol. 3, Journal of Anesthesia and Surgery. 2016. p. 1-9. Available from: http://dx.doi.org/10.15436/2377-1364.16.031

[18]. Okigbo RN, Mmeka EC. Antimicrobial effects of three tropical plant extracts on Staphylococcus aureus, Escherichia coli and Candida albicans. Afr J Tradit Complement Altern Med. 2008 Apr 10;5(3):226-9.Pubmed PMID: 20161941
[19]. Singhal G, Bhavesh R, Kasariya K, Sharma AR, Singh RP. Biosynthesis of silver nanoparticles using Ocimum sanctum (Tulsi) leaf extract and screening its antimicrobial activity. J Nanopart Res. 2011 Jul 1;13(7):2981-8.

[20]. Ritchie TJ, Ertl P, Lewis R. The graphical representation of ADME-related molecule properties for medicinal chemists. Drug Discov Today. 2011 Jan;16(1-2):65-72.Pubmed PMID: 21074634

[21]. Kelm MA, Nair MG, Strasburg GM, DeWitt DL. Antioxidant and cyclooxygenase inhibitory phenolic compounds from Ocimum sanctum Linn. Phytomedicine. 2000 Mar;7(1):7-13.Pubmed PMID: 10782484.

[22]. Amato L, Davoli M, Ferri M. Measures of outcomes in opiate detoxification trials: an experience of the Cochrane drugs and alcohol group [Internet]. Vol. 1, BMC News and views. 2001. Available from: http://dx.doi. org/10.1186/2048-4623-1-s3-pc138

[23]. Simonetti G, Santamaria AR, D'Auria FD, Mulinacci N, Innocenti M, Cecchini $\mathrm{F}$, et al. Evaluation of anti-Candida activity of Vitis vinifera L. seed extracts obtained from wine and table cultivars. Biomed Res Int. 2014;2014:127021.Pubmed PMID: 24864227.

[24]. Aref NS. An In Vitro Assessment of Surface Roughness, Tensile Bond Strength and Antifungal Activity of Grape Seed Extract-modified Soft Liner. J Contemp Dent Pract. 2020 Apr 1;21(4):353-358.Pubmed PMID: 32584268.

[25]. Bertolini MM, Portela MB, Curvelo JA, Soares RM, Lourenço EJ, Telles DM. Resins-based denture soft lining materials modified by chlorhexidine salt incorporation: an in vitro analysis of antifungal activity, drug release and hardness. Dent Mater. 2014 Aug;30(8):793-8.Pubmed PMID: 24933229.

[26]. Baygar T, Ugur A, Sarac N, Balci U, Ergun G. Functional denture soft liner with antimicrobial and antibiofilm properties. J Dent Sci. 2018 Sep;13(3):213-219.Pubmed PMID: 30895123.

[27]. Cohen MM. Tulsi - Ocimum sanctum: A herb for all reasons. J Ayurveda Integr Med. 2014 Oct-Dec;5(4):251-9.Pubmed PMID: 25624701

[28]. Miller R, Miller S. Tulsi queen of herbs. India’s Holy Basil. 2003. 